\title{
Chemical Free Two-Step Hydrothermal Pretreatment to Improve Sugar Yields from Energy Cane
}

\author{
Ankita Juneja ${ }^{1}$, Deepak Kumar ${ }^{2}$, Vijay Kumar Singh ${ }^{3}$, Yadvika ${ }^{4}$ and Vijay Singh ${ }^{1, *(\mathbb{D}}$ \\ 1 Agricultural and Biological Engineering, University of Illinois at Urbana-Champaign, Urbana, IL 61801, \\ USA; ajuneja@illinois.edu \\ 2 Department of Chemical Engineering, State University of New York College of Environmental Science and \\ Forestry, Syracuse, NY 13210, USA; dkumar02@esf.edu \\ 3 Department of Renewable and Bio-energy engineering, CCS Haryana Agricultural University, Hisar, \\ Haryana 12500, India; vijurss@gmail.com \\ 4 Department of Processing \& Food Engineering, CCS Haryana Agricultural University, Hisar, \\ Haryana 125004, India; yadvika6@yahoo.co.uk \\ * Correspondence: vsingh@illinois.edu; Tel.: +1-217-333-9510
}

Received: 8 October 2020; Accepted: 4 November 2020; Published: 6 November 2020

\begin{abstract}
Energy cane is an attractive lignocellulosic feedstock for processing into biofuels and bioproducts. A low-severity two-step hydrothermal pretreatment was investigated on energy cane for the production of monomeric sugar. Pretreatment temperature and time, in addition to the effect of disk milling, were observed for the glucose and xylose yields during hydrolysis. At residence times above $5 \mathrm{~min}$ in case of pretreatment at $200^{\circ} \mathrm{C}$, all of the hemicellulose was observed to be solubilized. The pretreatment condition of $200{ }^{\circ} \mathrm{C}$ for 10 min with disk milling was observed to provide the highest glucose concentration of $5.4 \%$, and $200{ }^{\circ} \mathrm{C}$ for $5 \mathrm{~min}$ with disk milling provided the highest xylose concentration of $2.15 \%$. The effect of disk milling in improving the sugar concentrations during hydrolysis was significant, especially at lower pretreatment temperatures and times. Low xylose yields at higher temperatures were attributed to the formation of degradation products at increased severity.
\end{abstract}

Keywords: energy cane; liquid hot water pretreatment; disk milling; sugar production; lignocellulosic biofuels

\section{Introduction}

Energy cane, unlike conventional sugarcane, is a non-food energy crop with high carbohydrate (fiber more than sucrose) content, abundant availability, and low cost, making it attractive renewable feedstock for sugar production that can be converted to biofuel, biochemicals, and other bio-based products [1]. Energy cane is a high yielding crop (about $90 \mathrm{MT} / \mathrm{ha}$ ) with almost double the fiber content and low sucrose compared to sugarcane [2]. Along with high fiber per unit land, the energy can also provide the advantages of relatively high cold-tolerance, lower fertilizer and water requirements, and less frequent replantation (10 years vs. 3 years for sugarcane), which makes it an ideal candidate for sustainable biofuel production $[3,4]$. 
Despite the numerous benefits of energy cane, like every cellulosic feedstock, the biomass recalcitrant structure remains one of the major challenges in its valorization process. Its structure consists of a highly complex matrix of cellulose, hemicellulose, and lignin, and a pretreatment is necessary to break this carbohydrate-lignin matrix to improve enzyme accessibility for efficient degradation. Some recent studies have investigated various chemical pretreatment processes, including dilute acid [5], dilute ammonia [6-8], and ionic liquid [3,9], and have reported high sugar recoveries during hydrolysis. However, these processes suffer from several limitations, including sugar loss, inhibitor formation, and the need of corrosion resistant equipment and neutralization along with high cost of the pretreatment reagent. Hot water pretreatment, also known as the "hydrothermal" or "auto-catalyzed" process, is an alternative efficient and environmentally friendly approach in which water acts at a very dilute acid due to the increased hydronium ion concentration at elevated temperatures and pressures [10-12]. The process avoids the use of chemicals and the need for specialized equipment; however, it requires about $20-50^{\circ} \mathrm{C}$ higher temperature and longer residence times compared with dilute acid pretreatment $[12,13]$. An important aspect to consider for pretreatment is better recovery of $\mathrm{C} 5$ sugars, which are lost with high severity biomass. Hemicellulose ranges from $25 \%$ to $35 \%$ of lignocellulosic biomass, and has potential and importance in the production of bioethanol, hydrogen, and added value compounds [14]. Although the hydrothermal pretreatment addresses several limitations of chemical process by minimizing the sugar loss and inhibitor formation, the subsequent cellulose conversion efficiencies have been observed to be relatively lower for some feedstocks $[12,15,16]$. The efficiency can be improved by combining the hydrothermal pretreatment with another physical pretreatment process, such as disk milling, ball milling, or extrusion [15]. Combined hot water and disk milling pretreatment has been observed to be a highly effective, energy-efficient, and cost-effective process to improve the hydrolysis yield of biomass [15,17]. Mechanical refining processes can be used as a standalone pretreatment process also but are highly energy-intensive when processing raw biomass, and the subsequent hydrolysis yields are also relatively lower. The energy required for the grinding/milling of already pretreated biomass (such as hot water or dilute acid pretreatment) could be up to $95 \%$ lower than processing raw biomass [12,18]. Combined liquid hot water (LHW) and disk milling synergistically reduce the biomass recalcitrance, increase the surface area, and yield high sugar recoveries during hydrolysis without the need for using chemicals.

Considering the limitations of chemical pretreatment processes and the increasing interest in using combined pretreatment technologies, the objective of this work was to investigate the effect of chemical-free two-stage mechanical thermal pretreatment, combining hot water pretreatment followed by the disk milling process, on improving the sugar yields from hydrolysis of energy cane bagasse. The effect of two parameters during liquid hot water (LHW) pretreatment, namely temperature and time, along with the effect of disk milling following the LHW, was investigated.

\section{Materials and Methods}

\subsection{Feedstock}

Energy cane bagasse (UFCP84-1047), dried after the extraction of juice, was obtained from the experimental field plots at the University of Florida, Gainesville, FL. Samples obtained were ground to pass through a $2.00 \mathrm{~mm}$ sieve using a hammer mill (model MHM4, Glen Mills, Clifton, NJ, USA). The ground sample was stored at $4{ }^{\circ} \mathrm{C}$ until used for experiments.

\subsection{Liquid Hot Water Pretreatment}

A simple schematic of the process used to produce sugars from energy cane is shown in Figure 1. All pretreatments were performed in $50 \mathrm{~mL}$ pipe reactors (stainless steel, 316 stainless, with $10.478 \mathrm{~cm}$ length $\times 1.905 \mathrm{~cm}$ o.d. $\times 0.165 \mathrm{~cm}$ wall thickness tubing; SS-T12-S-065-20, Swagelok, Chicago Fluid System Technologies, Chicago, IL, USA) using a fluidized sand bath (IFB-51 Industrial Fluidized Bath, Techne Inc., Burlington, NJ, USA) to provide the desired temperature. To obtain $20 \%$ solid loading, 
$8 \mathrm{~g}$ of ground energy cane (dry basis) was mixed with $32 \mathrm{~mL}$ of deionized (DI) water in the steel reactors. The reactors were closed with 316 stainless steel caps (SS-1210-C, Swagelok, Chicago Fluid System Technologies, Chicago, IL, USA). A full factorial design was used to conduct the experiments at three reaction temperatures, 160,180 , and $200^{\circ} \mathrm{C}$, and three residence times, 5, 10, and $15 \mathrm{~min}$, with three replicates for each condition. The temperature of the slurry in the reactors was monitored using a thermocouple (Penetration/Immersion Thermocouple Probe Mini Conn ( -418 to 1652 F), Mc Master-Carr, Robbinsville, NJ, USA) inserted into one reactor and connected to a data logger (HH306/306A, Datalogger Thermometer, Omega, Stamford, CT, USA). Rapid heating (within 5 min) in the sand bath was ensured for each pretreatment to reach its target temperature. The reactors were quenched in ambient temperature water right after pretreatment to lower the temperature of the reactors and stop the pretreatment reaction. During the cooling of reactors, the temperature dropped more than $100{ }^{\circ} \mathrm{C}$ in less than $1 \mathrm{~min}$.

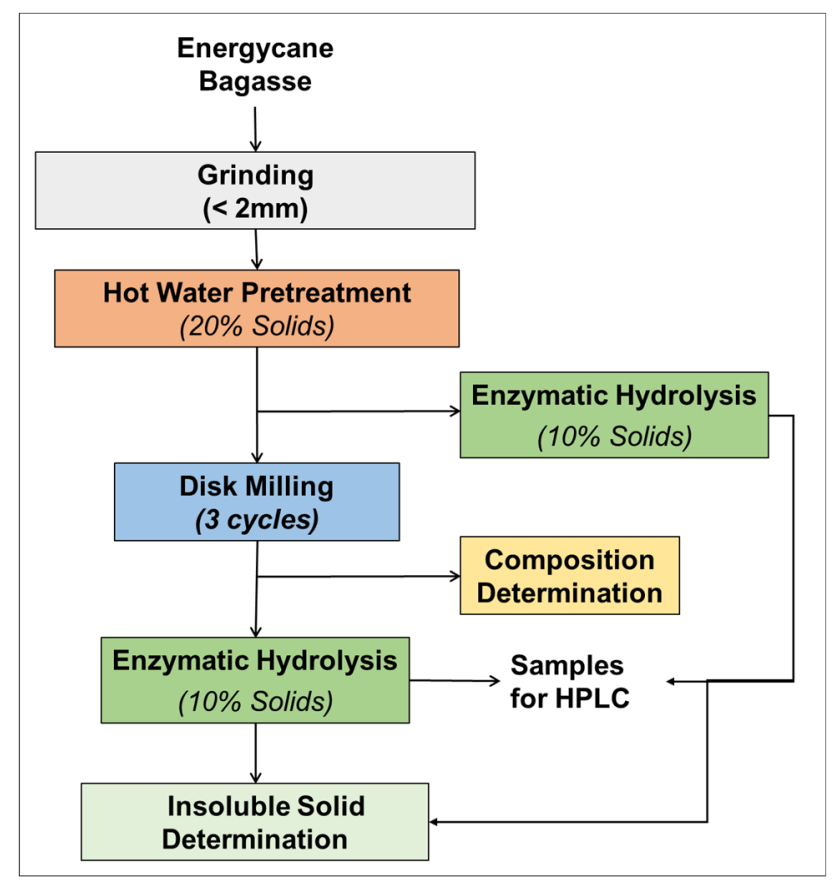

Figure 1. Schematic of the process utilized to convert energy cane to sugar monomers.

The severity parameter $\left(\mathrm{R}_{0}\right)$ of the pretreatment is generally defined as equation $1[12,19]$, where $t$ is reaction time $(\mathrm{min}), \mathrm{T}$ is pretreatment temperature $\left({ }^{\circ} \mathrm{C}\right)$, and $\mathrm{T}_{\mathrm{R}}$ is reference temperature $\left(100^{\circ} \mathrm{C}\right)$. $\log \left(\mathrm{R}_{0}\right)$ was calculated to report the severity factor [20].

$$
\mathrm{R}_{0}=\mathrm{t} \cdot \exp \left\{\left(\mathrm{T}-\mathrm{T}_{\mathrm{R}}\right) / 14.75\right\}
$$

\subsection{Disk Milling/Mechanical Refining}

Without washing, neutralization, or separation, the recovered samples from the pretreatment reactors from each pretreatment condition were passed though disk milling three times. The pretreated samples were mechanically refined by using the disk mill (Quaker City grinding mill model 4E, Straub Co., Philadelphia, PA, USA), with two plates: rotating and stationary. The gap between the two plates was set to minimal (about zero) with an output speed of $89 \mathrm{rpm}$. Based on results from preliminary studies, the disk milling of pretreated biomass was limited to three sequential milling cycles, to reduce energy, cost, moisture loss, and heat generation during the process [12]. 


\subsection{Chemical Composition of Raw and Pretreated Energy Cane Biomass}

Compositional analysis of untreated (raw) and pretreated biomass was carried out according to the Laboratory Analytical Procedure for biomass analysis from the National Renewable Energy Laboratory (NREL). Pretreated biomass samples were frozen for $24 \mathrm{~h}$ at $-20^{\circ} \mathrm{C}$, followed by freeze drying (Laconco, Kansas City, MO, USA) for $72 \mathrm{~h}$ before analysis. Samples obtained after freeze drying were analyzed for chemical composition (extractives, cellulose, hemicellulose, acid soluble lignin, and acid insoluble lignin).

Extractives were removed by water and ethanol extraction using the Soxhlet method based on NREL/TP-510-42619 (2008). Extractive free biomass was used in a two-step hydrolysis adapted for measuring carbohydrate content in the biomass. In summary, $0.3 \mathrm{~g}$ of biomass is mixed with $3 \mathrm{~mL}$ of $72 \%$ sulfuric acid and incubated in a water bath at $30{ }^{\circ} \mathrm{C}$ for $1 \mathrm{~h}$, with frequent stirring. The acid concentration was then diluted to $4 \%$ by adding $84 \mathrm{~mL}$ of deionized water in the sample, followed by autoclaving at $121^{\circ} \mathrm{C}$ for $1 \mathrm{~h}$. After the two-step acid hydrolysis, hydrolyzed samples were vacuum filtered using filter crucibles. The solids on the filter were analyzed for acid insoluble lignin (AIL) by drying the filter crucible in the oven at $105^{\circ} \mathrm{C}$ for $24 \mathrm{~h}$ followed by combusting in a muffle furnace at $575{ }^{\circ} \mathrm{C}$ for $4 \mathrm{~h}$. The filtrate was analyzed for acid soluble lignin (ASL) by recording the absorbance of sample at $205 \mathrm{~nm}$. The filtrate was also neutralized and analyzed for sugar concentration by HPLC equipped with a refractive index detector (Aminex HPX-87P, Bio-Rad, Hercules, CA, USA).

\subsection{Enzymatic Hydrolysis}

Enzymatic hydrolysis was performed on the pretreated slurry following NREL/TP-5100-63351 procedures. Enzymatic hydrolysis was performed with samples from only LHW pretreatment, and from LHW pretreatment followed by three cycles of disk milling, to observe the effect of mechanical refining on the sugar yields during hydrolysis. Hydrolysis was conducted at $10 \%$ solids loading at a $25 \mathrm{~mL}$ scale in $50 \mathrm{~mL}$ Corning tubes. Pretreated samples were transferred into sterilized tubes (Corning), and $1 \mathrm{M}$ sodium citrate buffer $(\mathrm{pH} 4.5)$ was used to adjust the $\mathrm{pH}$ to 5.0 bringing a final concentration of $0.05 \mathrm{M}$ citrate buffer. Deionized water along with cellulase and hemicellulose cocktails were added to bring the final solid content to $10 \%$. Cellic $® C$ tec2 and Cellic $(H t e c 2$ (Novozymes North America, Inc., Franklinton, NC, USA) at $0.215 \mathrm{~mL} / \mathrm{g}$ dry substrate (30 FPU/g) and $0.054 \mathrm{~mL} / \mathrm{g}$ dry substrate, respectively, were used for enzymatic hydrolysis. The slurry was kept at $50^{\circ} \mathrm{C}$ in an incubator shaker at $120 \mathrm{rpm}$ for $72 \mathrm{~h}$. Aliquots $(0.4 \mathrm{~mL})$ were taken at $0,4,8,24,48$, and $72 \mathrm{~h}$ for glucose, xylose, and organic acids measurements. Three replicates were used for each experiment.

\subsection{Sugar Recovery and Hydrolysis Efficiency}

The hydrolysis sugar recovery was defined as the ratio of sugar yield (obtained by subtracting the zero-point sugars, produced during pretreatment) at any time point to theoretical yield from carbohydrate contents in pretreated biomass under that condition. At the end of the hydrolysis, the slurry was filtered with a pre-weighed Wattman No. 4 cellulose filter paper, and the density of the filtrate was calculated with measured volume and weight. The solids on the filter were washed with $50 \mathrm{~mL}$ water and dried in the oven to obtain the weight of insoluble solids. The sugar concentrations were converted to percent sugar recovery based on the composition of the pretreated energy cane, the insoluble solids left after hydrolysis, and the density of the hydrolysate.

\subsection{HPLC Analysis}

The samples obtained at different time points were centrifuged at $9729 \mathrm{~g}(5415 \mathrm{D}$, Brinkmann Eppendorf, Hamburg, Germany) for $10 \mathrm{~min}$. The top clear phase was passed through $0.2 \mu \mathrm{m}$ syringe filters (nylon Acrodisc WAT200834, Pall Life Sciences, Port Washington, NY) into $150 \mu \mathrm{L}$ HPLC vials. The vials were stored at $4{ }^{\circ} \mathrm{C}$ immediately, until analyzed. The filtrate was analyzed using HPLC with an ion-exclusion column (Aminex HPX-87H, Bio-Rad, Hercules, CA, USA). The mobile phase used 
was $0.005 \mathrm{M}$ sulfuric acid at $50{ }^{\circ} \mathrm{C}$ with a flow rate of $0.6 \mathrm{~mL} / \mathrm{min}$. Carbohydrates and organic acids were measured with a refractive index detector (model 2414, Waters Corporation, Milford, MA, New Zealand) using multiple standards. HPLC samples were analyzed with a lowest detection limit of $0.001 \% w / v$.

\subsection{Statistical Analysis}

All the results were presented as average \pm standard deviation. To compare the sugar concentrations, one-way ANOVA (analysis of variance) and Fisher's least significant difference (LSD) tests were used (SAS version 9.4). A $5 \%(p<0.05)$ level was selected to determine statistical significance in all cases.

\section{Results and Discussion}

\subsection{Chemical Compositional of Raw and Pretreated Energycane Bagasse}

Glucans, xylans, extractives, acid soluble lignin (ASL), and acid insoluble lignin (AIL) were measured for raw biomass as well as for hot water pretreated biomass in nine conditions to observe the effect of pretreatment on energy cane composition (Table 1). The post-LHW pretreatment slurry was freeze-dried, and the samples were used to perform composition analysis. The raw biomass (on dry basis (db)) contained about 55\% carbohydrates (glucans and xylans), and the remaining components were extractives, acid insoluble lignin (AIL), and acid soluble lignin (ASL) (in order of abundance), which was in the range of previously reported compositions of energy cane [2,3]. After pretreatment, the glucans concentration was between $31.48 \%$ and $41.58 \%$, with the maximum concentration found in the sample pretreated at $200{ }^{\circ} \mathrm{C}$ for $15 \mathrm{~min}$ (highest severity). This was not unexpected, since in this condition, all of the xylans and most of the soluble lignin were solubilized. Extractives (including both water-soluble and ethanol-soluble) increased with the pretreatment temperature and time, and the highest extractives were observed at $200{ }^{\circ} \mathrm{C}$ for $15 \mathrm{~min}$. Similar results have been previously reported for pretreatment of another lignocellulosic biomass, sugarcane bagasse [16]. The major reason for higher extractives is the higher formation of degradation products with the increasing severity of the pretreatment, which are removed during the extraction process [21]. One of the major outcomes of pretreatment is the solubilization of hemicellulose due to autohydrolysis, resulting in decreased xylans with the increase in temperature and time of pretreatment [22,23]. In addition, harsher pretreatment conditions (higher temperatures and times) degrade the hexoses and pentoses into furfural and 5-hydroxylmethyl furfural, respectively [5]. Similar results were obtained in this study, and no xylan content was observed at the pretreatment temperature of $200{ }^{\circ} \mathrm{C}$ for 10 and $15 \mathrm{~min}$. Another study reported hemicellulose content of $1.1 \%$ after hot compressed water pretreatment for $20 \mathrm{~min}$ at $200^{\circ} \mathrm{C}$ for oil palm mesocarp fiber [24]. The amount of soluble lignin decreased with the increase in severity of the pretreatment, which is expected, since an increase in delignification has also been previously reported with an increase in the severity factor of the pretreatment [16].

Table 1. Composition analysis for untreated and pretreated energy cane.

\begin{tabular}{|c|c|c|c|c|c|c|}
\hline $\begin{array}{l}\text { Pretreatment } \\
\text { Temp }\left({ }^{\circ} \mathrm{C}\right)\end{array}$ & $\begin{array}{l}\text { Pretreatment } \\
\text { Time (min) }\end{array}$ & $\begin{array}{c}\text { Extractives } \\
(\%, d b)\end{array}$ & $\begin{array}{c}\text { Glucans } \\
(\%, d b)\end{array}$ & $\begin{array}{l}\text { Xylans } \\
(\%, d b)\end{array}$ & $\begin{array}{c}\text { Insoluble } \\
\text { Lignin }(\%, \mathrm{db})\end{array}$ & $\begin{array}{c}\text { Soluble Lignin } \\
(\%, \mathrm{db})\end{array}$ \\
\hline \multicolumn{2}{|c|}{ Untreated } & 18.62 & 34.77 & 20.16 & 15.37 & 2.08 \\
\hline 160 & 5 & 15.70 & 32.32 & 16.32 & 14.06 & 1.78 \\
\hline 160 & 10 & 18.04 & 33.71 & 15.88 & 13.96 & 1.60 \\
\hline 160 & 15 & 36.33 & 32.04 & 10.39 & 9.22 & 1.00 \\
\hline 180 & 5 & 18.40 & 34.31 & 16.70 & 13.48 & 1.58 \\
\hline 180 & 10 & 33.69 & 31.48 & 8.56 & 11.70 & 0.57 \\
\hline 180 & 15 & 29.78 & 32.73 & 9.07 & 12.54 & 0.67 \\
\hline 200 & 5 & 41.54 & 34.15 & 4.40 & 10.32 & 0.73 \\
\hline 200 & 10 & 45.16 & 37.07 & 0.00 & 10.78 & 0.38 \\
\hline 200 & 15 & 45.51 & 41.58 & 0.00 & 10.23 & 0.37 \\
\hline
\end{tabular}




\subsection{Effect of Liquid Hot Water Pretreatment Followed by Disk Milling on Sugar Yields}

Pretreatment is a key cost center for commercial processing of lignocellulosic biomass; however, it is essential for releasing high sugars for conversion into bioproducts economically on a commercial scale [25]. The pretreatment temperature and time were observed to be critical factors in obtaining high sugar yields in comparison with untreated biomass $(p<0.05)$. The hydrolysis profile for samples pretreated at $160{ }^{\circ} \mathrm{C}, 180^{\circ} \mathrm{C}$, and $200{ }^{\circ} \mathrm{C}$ are shown in Figures $2-4$, respectively. At $160{ }^{\circ} \mathrm{C}$, the rate of hydrolysis as well as the final glucose concentration were higher for all three residence times, in comparison with the untreated biomass. The sugar concentration was observed to increase with an increase in time from 5 to $10 \mathrm{~min}$; however, the final glucose concentration for $10 \mathrm{~min}(2.45 \%)$ and $15 \mathrm{~min}(2.49 \%)$ was significantly similar (about $65 \%$ higher than the untreated biomass). Xylose concentration, however, did not increase with pretreatment for $5 \mathrm{~min}$ (mainly because $5 \mathrm{~min}$ was not enough to solubilize enough hemicellulose), but had a significant increase for pretreatment times of 10 and $15 \mathrm{~min}$ (44\% and 51\% higher than the untreated biomass, respectively). The glucose release at the end of the hydrolysis for samples pretreated at $160{ }^{\circ} \mathrm{C}$ was measured as $58.29 \%, 60.18 \%$, and $63.59 \%$ for 5, 10, and $15 \mathrm{~min}$ of pretreatment, respectively. All the three values were calculated based on the glucose concentration in the pretreated biomass that is left unconverted during pretreatment.

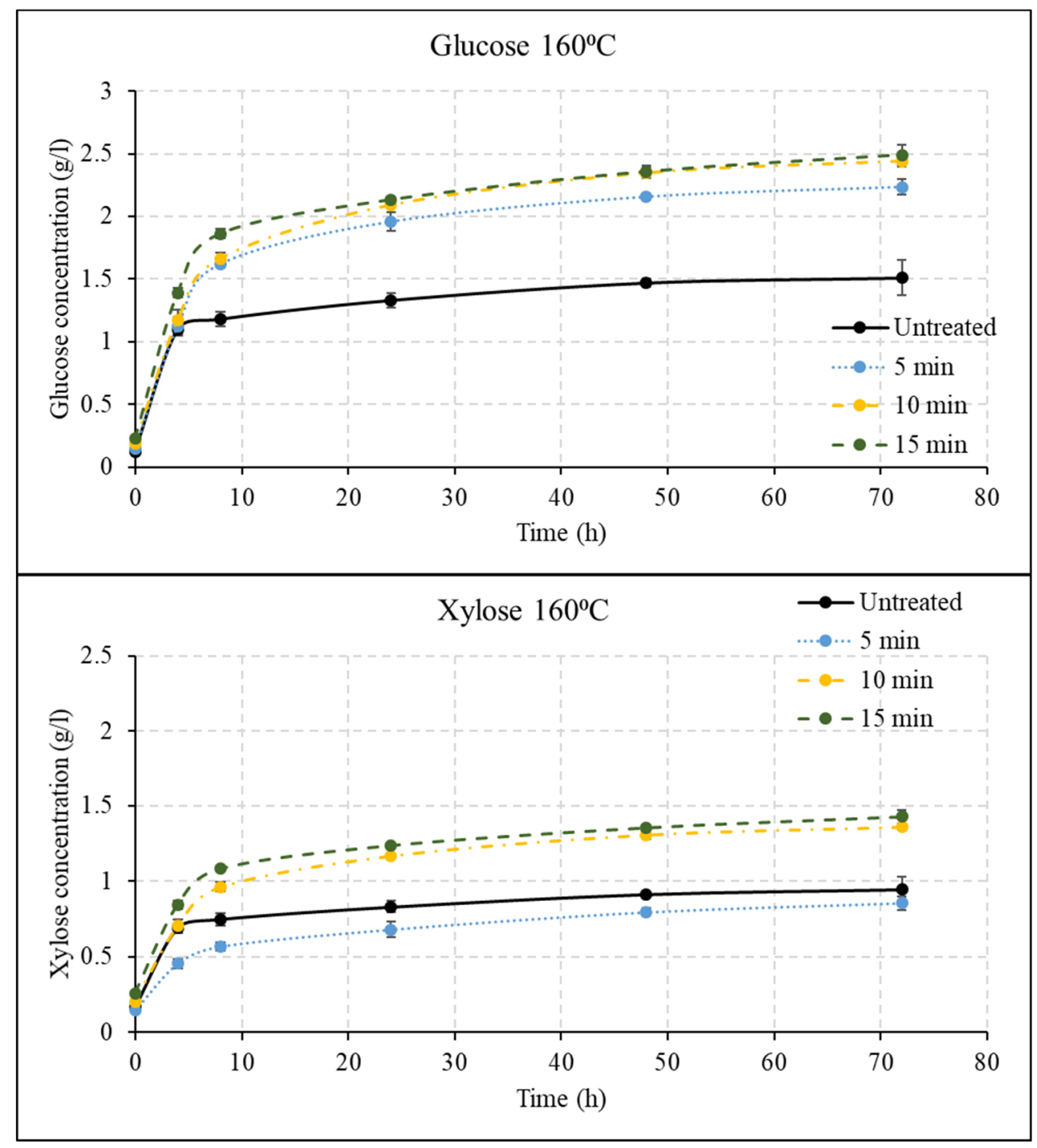

Figure 2. Hydrolysis profile for samples pretreated at $160{ }^{\circ} \mathrm{C}$ for 5,10 , and $15 \mathrm{~min}$, followed by disk milling. 
A similar trend was observed for hydrolysis with samples pretreated at $180{ }^{\circ} \mathrm{C}$, as the final glucose and xylose concentrations were statistically similar for 10 and $15 \mathrm{~min}$, both of which were significantly different from $5 \mathrm{~min}$ and untreated biomass. The final glucose $(3.5 \%)$ and xylose $(1.89 \%)$ for $10-$ and $15-\mathrm{min}$ pretreatment times were about $133 \%$ and $100 \%$ higher than those for untreated biomass, respectively. The final glucose release for all three pretreatment times at $180{ }^{\circ} \mathrm{C}$ was in the range of $55 \%$ to $87 \%$. Hydrolysis of energy cane bagasse pretreated with ionic liquid has been reported to provide cellulose digestibility of $64 \%$ to $87 \%$, depending on enzyme dosage [3], which is in range of the results obtained in this study. Ionic liquid pretreatment suffers from economic constraints, making the LHW pretreatment with similar sugar yields more attractive [26]. The xylose concentration for samples pretreated at $200{ }^{\circ} \mathrm{C}$ showed an inverse relation of xylose concentration with increasing pretreatment time. In addition, the xylose concentration was observed to increase for the first $4 \mathrm{~h}$ but stayed constant thereafter. This is expected because in severe pretreatment conditions, hemicellulose solubilizes and is more likely to form inhibitors [16]. Similar results of decreasing xylose concentration with increasing severity were observed after pretreatment of energy cane bagasse with dilute ammonia [8]. Overall, the maximum glucose concentration achieved with $20{ }^{\circ} \mathrm{C}$ was $5.4 \%$, both at 10 - and 15-min pretreatment time, which was $258 \%$ higher than the untreated biomass; however, the maximum xylose concentration was obtained for 5 min pretreatment $(2.149 \%)$, which was $127 \%$ higher than that of untreated biomass. At all temperatures, the glucose production profiles and final glucose concentrations were similar for 10 and 15 min residence time.

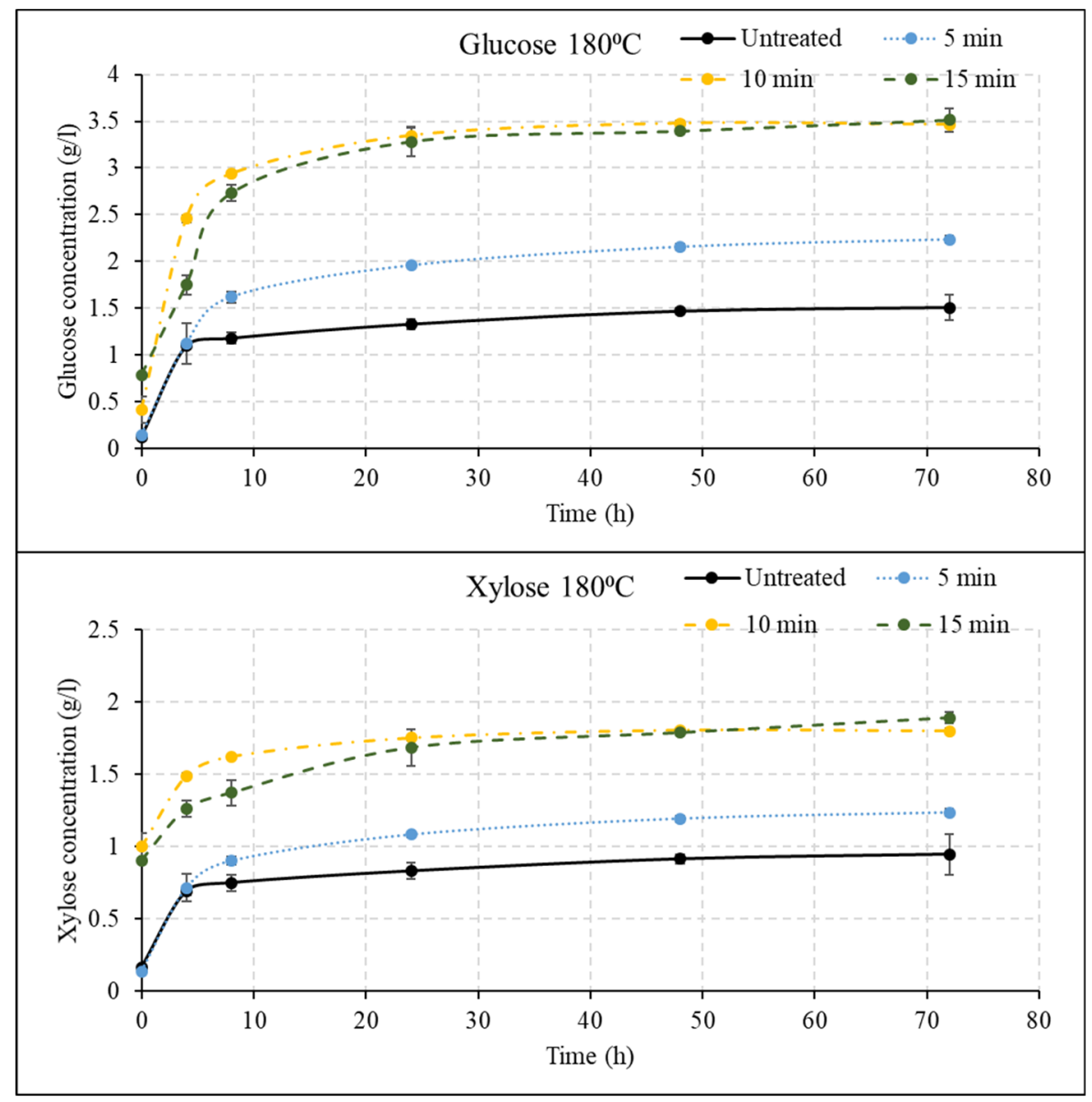

Figure 3. Hydrolysis profile for samples pretreated at $180{ }^{\circ} \mathrm{C}$ for 5,10 , and $15 \mathrm{~min}$, followed by disk milling. 


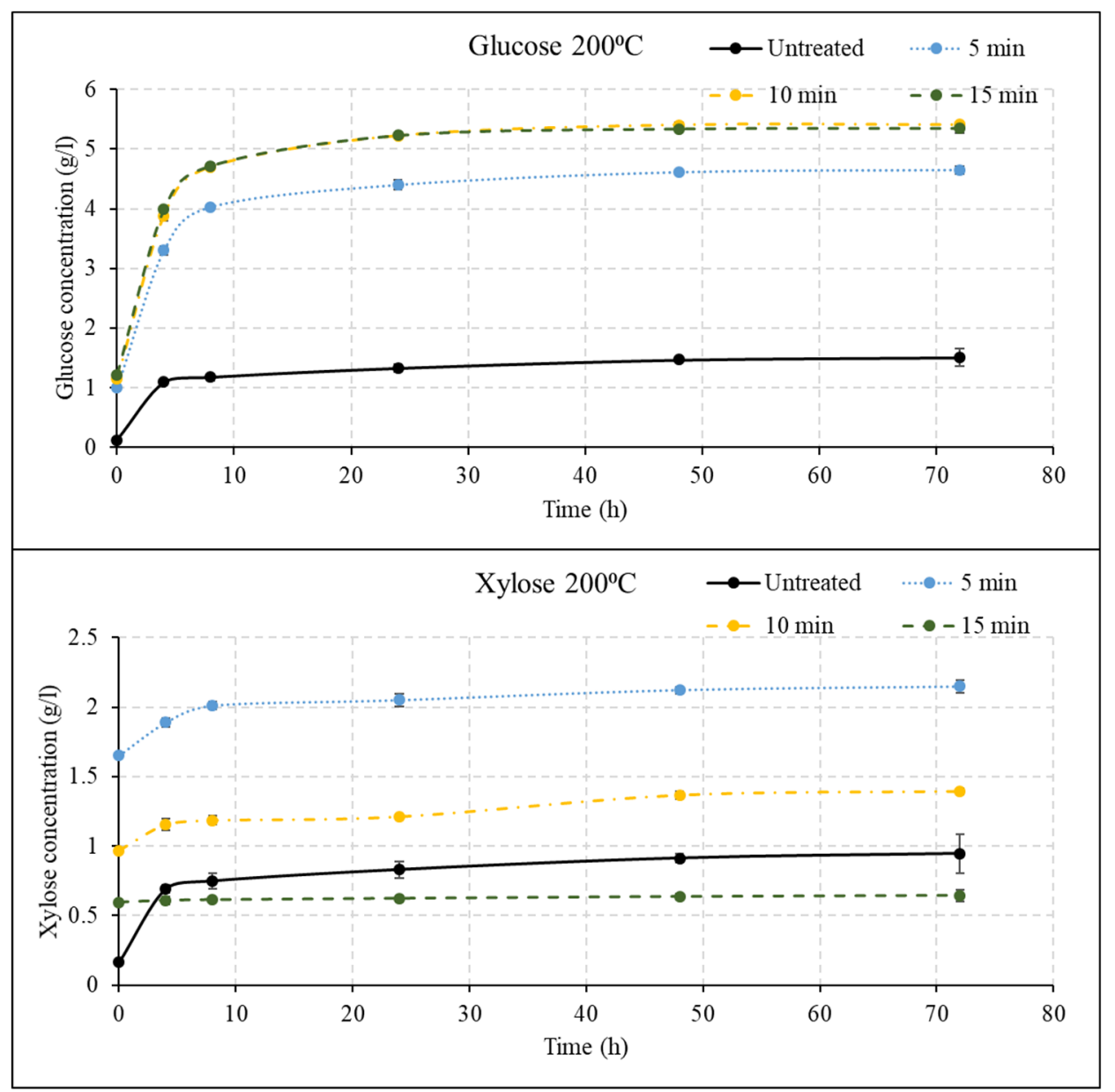

Figure 4. Hydrolysis profile for samples pretreated at $200{ }^{\circ} \mathrm{C}$ for 5,10 , and $15 \mathrm{~min}$, followed by disk milling.

\subsection{Effect of Disk Milling on Sugar Yields}

The final glucose and xylose concentration obtained after enzymatic hydrolysis for samples with and without the mechanical refining step are shown in Figure 5. The average glucose and xylose concentrations with disk milling ranged from $2.23 \%$ to $5.40 \%$ and $0.64 \% 2.15 \%$, respectively, whereas average glucose and xylose concentrations without disk milling varied between $1.62 \%$ to $5.30 \%$ and $0.45 \%$ to $1.93 \%$, respectively. Disk milling was observed to have a synergistic effect with LHW pretreatment to obtain high glucose and xylose concentrations. Disk milling leads to class I size reduction (shear forces increasing external surface area via delamination) and class II size reduction (deconstructing cell walls by breaking microfibril cross links and compression induced internal fibrillation) [27]. The effect of disk milling was more predominant at lower temperatures and times, which has also been observed previously for sugarcane bagasse [16]. For $160{ }^{\circ} \mathrm{C}$ pretreatment temperature, the addition of disk milling provided $37.75 \%, 49.09 \%$, and $35.94 \%$ higher glucose concentrations for 5, 10, and 15 min pretreatment times, respectively, in comparison with no disk milling. A $26.16 \%$ and $34.34 \%$ increase in glucose was observed with the addition of three passes of disk milling in pretreatment conditions $180^{\circ} \mathrm{C}, 10 \mathrm{~min}$ and $200{ }^{\circ} \mathrm{C}, 5 \mathrm{~min}$. At $200{ }^{\circ} \mathrm{C}$, extending the LHW pretreatment time beyond $5 \mathrm{~min}$, the differences between disk-milled and non-milled samples were very limited. The hydrolysis yields are highly dependent on the process conditions, mainly the temperature and time used during the hot water pretreatment. It has been observed that the secondary disk milling process might not be required for all feedstocks, and only hot water pretreatment in certain conditions might be sufficient. Kumar and Murthy [28] observed no significant difference in the 
sugar yields during hydrolysis of hot water and dilute acid pretreated tall fescue and bentgrass straw; however, the yield was higher for dilute acid pretreated samples for perennial ryegrass straw [28]. For xylose concentrations, the increase in disk-milled samples was in the range of $2.5 \%$ to $53.4 \%$. Similar results were obtained previously, where addition of wet disk milling showed an increase of $34-89 \%$ for glucose and $4-134 \%$ for glucose using corn stover [12].

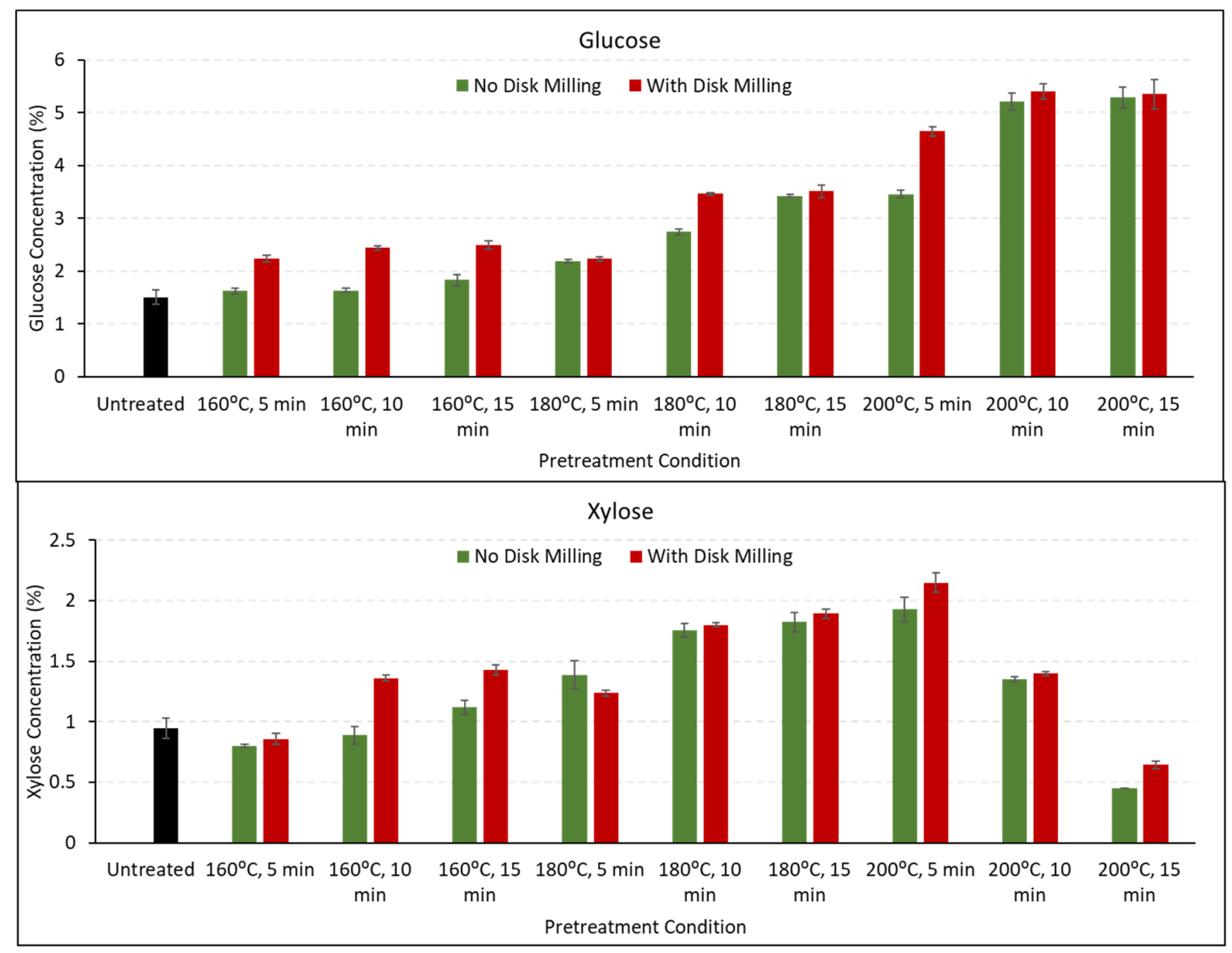

Figure 5. Effect of disk milling on enzymatic hydrolysis of energy cane.

\subsection{Hydrolysis Efficiency}

Glucose recoveries based on theoretical unconverted glucose present in the pretreated biomass under different pretreatment conditions are presented in Figure 6. The glucose recovery ranged from $36.10 \%$ to $94.78 \%$ for non-disk-milled samples, and from $48.16 \%$ to $96.55 \%$ for the disk-milled samples, with the highest sugar recovery at $200^{\circ} \mathrm{C}, 10 \mathrm{~min}$ pretreatment conditions $(\mathrm{SF}=3.94)$ during hydrolysis. However, in this condition, the recovery from the disk-milled samples was only $1.8 \%$ higher than that for the non-disk-milled samples. Similar high glucose recovery was obtained at $180{ }^{\circ} \mathrm{C}, 15 \mathrm{~min}$ $(95.26 \%)$, which was $6.8 \%$ higher than the samples pretreated in the same condition but not disk-milled (Figure 6). The effect of disk milling was more predominant at all times for $160{ }^{\circ} \mathrm{C}$, which has been previously reported [16]. The recovery observed at $180^{\circ} \mathrm{C}, 15 \mathrm{~min}$ and disk milling corresponds to over $98 \%$ of the maximum glucose value recovered. Thus, disk milling permitted to achieve almost maximum hydrolysis efficiency while operating at a lower temperature of $20^{\circ} \mathrm{C}$ for only 5 min more, highlighting a synergy between the pretreatments that helps mitigate the process conditions. 


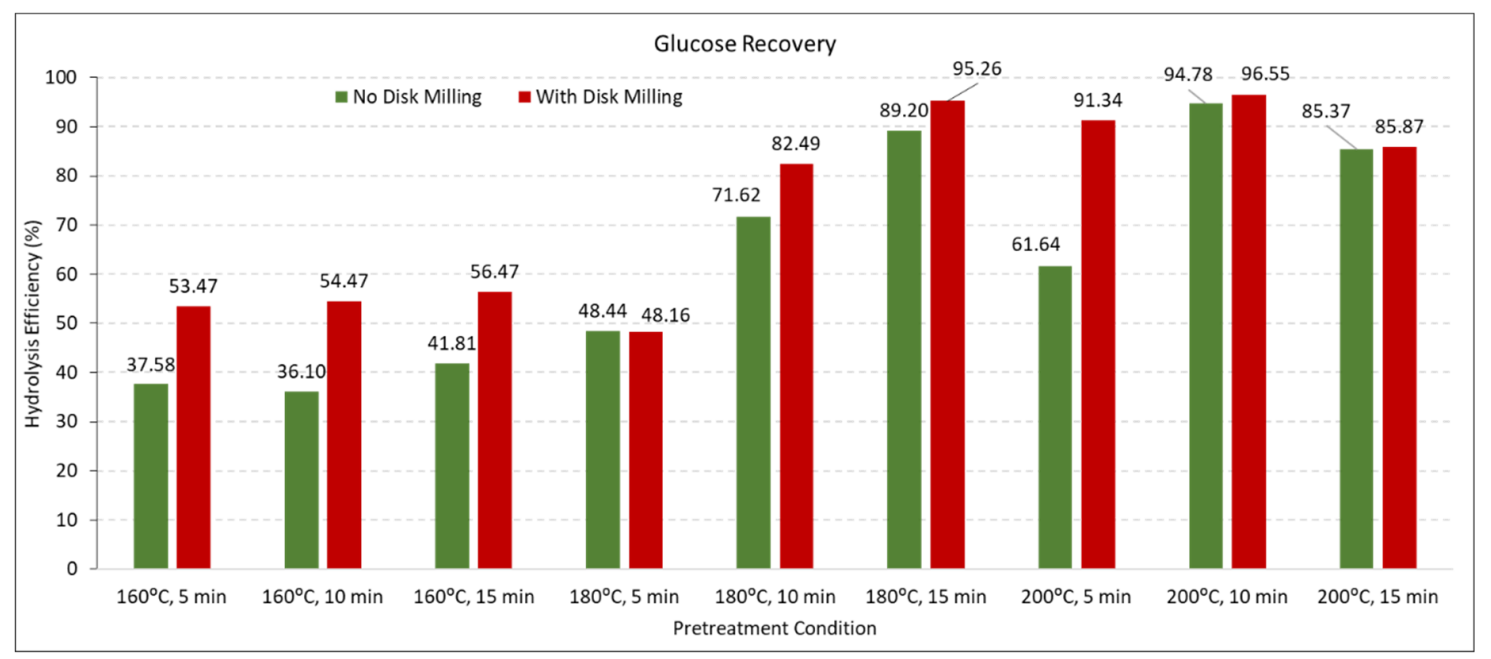

Figure 6. Glucose recovery at the end of hydrolysis for biomass pretreated at nine conditions.

Xylose recovery was calculated based on raw biomass composition as well as on pretreated biomass composition (Table 2). The xylose recovery from untreated energy cane was measured as $5.5 \%$, which is similar to $5.8 \%$ reported previously for untreated oil palm mesocarp fiber with similar hemicellulose content as energy cane [24]. On the basis of raw biomass composition, xylose yields at the end of the hydrolysis ranged from $2 \%$ to $45.5 \%$ for LHW pretreatment and from $26.86 \%$ to $88.67 \%$ for LHW followed by disk milling pretreatment. Previous studies have reported maximum xylose yields of $54.3 \%$ with LHW pretreated corn stover followed by nine cycles of disk milling [12], $50.50 \%$ with sugarcane bagasse pretreated by ozonolysis followed by seven cycles of disk milling [29], and $66.6 \%$ for LHW of sugarcane bagasse followed by three cycles of disk milling [16]. The xylose recovery in the current study is higher than all the yields previously reported only with three cycles of disk milling. This might suggest that different biomass, with varying levels of recalcitrance, requires different severity of pretreatment to release sugars. Also, different types of pretreatments can have varying effects on the same biomass, affecting the number of disk milling cycles needed to obtain the maximum possible sugar release. Based on the composition of pretreated biomass, xylose yields were in the range of 35\%-94\% for non-disk-milled samples and exceeded $100 \%$ for disk-milled samples in higher severity conditions (3.53-4.12). This observation is attributed to the fact that liquid hot water pretreatment (as severity increases) solubilizes the hemicellulose into liquid as soluble oligosaccharides, which are not detected as xylose, and break down during the hydrolysis process [30]. These oligomers, being soluble, are removed in extractives (rather than being measured as hemicellulose) during the estimation of composition of the pretreated biomass. Due to same reason, no xylose was detected in the composition of the biomass pretreated at $200^{\circ} \mathrm{C}$ for 10 and $15 \mathrm{~min}$; therefore, xylose recovery was also not obtained in these conditions.

Table 2. Xylose recovery based on the composition of raw biomass and pretreated biomass.

\begin{tabular}{|c|c|c|c|c|c|c|c|c|c|c|}
\hline \multirow[b]{2}{*}{$\begin{array}{c}\text { Basis of } \\
\text { Calculation }\end{array}$} & & \multicolumn{9}{|c|}{ Xylose Recovery, \% } \\
\hline & & $\begin{array}{l}160^{\circ} \mathrm{C}, \\
5 \mathrm{~min}\end{array}$ & $\begin{array}{l}160^{\circ} \mathrm{C}, \\
10 \mathrm{~min}\end{array}$ & $\begin{array}{l}160^{\circ} \mathrm{C}, \\
15 \mathrm{~min}\end{array}$ & $\begin{array}{l}180^{\circ} \mathrm{C}, \\
5 \mathrm{~min}\end{array}$ & $\begin{array}{l}180^{\circ} \mathrm{C}, \\
10 \mathrm{~min}\end{array}$ & $\begin{array}{l}180^{\circ} \mathrm{C}, \\
15 \mathrm{~min}\end{array}$ & $\begin{array}{c}200^{\circ} \mathrm{C}, \\
5 \mathrm{~min}\end{array}$ & $\begin{array}{l}200{ }^{\circ} \mathrm{C}, \\
10 \mathrm{~min}\end{array}$ & $\begin{array}{l}200^{\circ} \mathrm{C}, \\
15 \mathrm{~min}\end{array}$ \\
\hline Raw biomass & No DM* & 28.36 & 45.48 & 45.239 & 41.9 & 32.88 & 41.16 & 20.48 & 17.31 & 2.058 \\
\hline composition & $\mathrm{DM}^{*}$ & 34.14 & 53.53 & 55.155 & 47.15 & 74.08 & 78.9 & 88.67 & 56.61 & 26.86 \\
\hline Pretreated biomass & No DM* & 35.04 & 57.72 & 87.8 & 50.59 & 77.44 & 91.47 & 93.83 & - & - \\
\hline composition & $\mathrm{DM}^{*}$ & 80.42 & 119 & 66.6 & 58.26 & 94.01 & 153.1 & 406.2 & - & - \\
\hline
\end{tabular}

*DM: liquid hot water (LHW) pretreatment followed by three cycles of disk milling. *No DM: LHW pretreatment only. 


\section{Conclusions}

A chemical-free two-step pretreatment was investigated for efficient sugar production from energy cane bagasse. Three liquid hot water pretreatment (LHW) temperatures $\left(160^{\circ} \mathrm{C}, 180^{\circ} \mathrm{C}\right.$, and $\left.200{ }^{\circ} \mathrm{C}\right)$ and three residence times $(5,10$, and $15 \mathrm{~min})$ were investigated, in addition to understanding the effect of disk milling following LHW on the sugar yields. During pretreatment at $200{ }^{\circ} \mathrm{C}$, residence times of more than $5 \mathrm{~min}$ solubilized all the hemicellulose. The highest glucose concentration of $5.4 \%$ was obtained for the pretreatment condition of $200^{\circ} \mathrm{C}$ for $10 \mathrm{~min}$ with disk milling, and the highest xylose concentration of $2.15 \%$ was obtained for $200{ }^{\circ} \mathrm{C}$ for $5 \mathrm{~min}$ with disk milling. Disk milling improved the sugar yields; however, the effect was more predominant at lower pretreatment temperatures and times. With the increase in the severity of pretreatment, the xylose content decreased as expected due to the formation of degradation products, such as 5-hydroxymethylfurfural (5-HMF).

Author Contributions: Conceptualization, V.S. and D.K.; methodology, D.K. and A.J.; formal analysis, A.J. and D.K.; investigation, A.J., V.K.S., and Y.; data curation, A.J. and D.K.; writing-original draft preparation, A.J. and D.K.; writing - review and editing, V.S. All authors have read and agreed to the published version of the manuscript.

Funding: The information, data, and work presented herein were funded in part by the Biological and Environmental Research (BER) program, U.S. Department of Energy, under Award Number DE-SC0018254. The views and opinions of authors expressed herein do not necessarily state or reflect those of the United States Government or any agency thereof.

Conflicts of Interest: The authors declare no conflict of interest.

\section{References}

1. Matsuoka, S.; Kennedy, A.J.; Santos, E.G.D.D. Energy cane: Its concept, development, characteristics, and prospects. Adv. Bot. 2014, 2014, 597275. [CrossRef]

2. Aragon, D.; Lu, S.; Kochergin, V. Conversion of energy cane and sweet sorghum into biofuels and chemicals: A modeling approach. In Proceedings of the Joint Annual Meeting of the Association for the Advancement of Industrial Crops and the USDA National Institute of Food and Agriculture, Washington, DC, USA, 12-16 October 2013.

3. Qiu, Z.; Aita, G.M.; Walker, M.S. Effect of ionic liquid pretreatment on the chemical composition, structure and enzymatic hydrolysis of energy cane bagasse. Bioresour. Technol. 2012, 117, 251-256. [CrossRef] [PubMed]

4. Kim, M.; Day, D.F. Composition of sugar cane, energy cane, and sweet sorghum suitable for ethanol production at Louisiana sugar mills. J. Ind. Microbiol. Biotechnol. 2011, 38, 803-807. [CrossRef] [PubMed]

5. Suhardi, V.S.H.; Prasai, B.; Samaha, D.; Boopathy, R. Evaluation of pretreatment methods for lignocellulosic ethanol production from energy cane variety L 79-1002. Int. Biodeterior. Biodegrad. 2013, 85, 683-687. [CrossRef]

6. Deng, F.; Aita, G.M. Detoxification of dilute ammonia pretreated energy cane bagasse enzymatic hydrolysate by soluble polyelectrolyte flocculants. Ind. Crop. Prod. 2018, 112, 681-690. [CrossRef]

7. Aita, G.; Salvi, D.; Walker, M. Enzyme hydrolysis and ethanol fermentation of dilute ammonia pretreated energy cane. Bioresour. Technol. 2011, 102, 4444-4448. [CrossRef]

8. Oladi, S.; Aita, G.M. Interactive effect of enzymes and surfactant on the cellulose digestibility of un-washed and washed dilute ammonia pretreated energy cane bagasse. Biomass Bioenergy 2018, 109, 221-230. [CrossRef]

9. Qiu, Z.; Aita, G.M.; Mahalaxmi, S. Optimization by response surface methodology of processing conditions for the ionic liquid pretreatment of energy cane bagasse. J. Chem. Technol. Biotechnol. 2014, 89, 682-689. [CrossRef]

10. Kumar, D.; Murthy, G.S. Impact of pretreatment and downstream processing technologies on economics and energy in cellulosic ethanol production. Biotechnol. Biofuels 2011, 4, 27. [CrossRef]

11. Mood, S.H.; Golfeshan, A.H.; Tabatabaei, M.; Jouzani, G.S.; Najafi, G.H.; Gholami, M.; Ardjmand, M. Lignocellulosic biomass to bioethanol, a comprehensive review with a focus on pretreatment. Renew. Sustain. Energy Rev. 2013, 27, 77-93. [CrossRef] 
12. Kim, S.M.; Dien, B.S.; Tumbleson, M.E.; Rausch, K.D.; Singh, V. Improvement of sugar yields from corn stover using sequential hot water pretreatment and disk milling. Bioresour. Technol. 2016, 216, 706-713. [CrossRef] [PubMed]

13. Mosier, N.S. Fundamentals of aqueous pretreatment of biomass. In Aqueous Pretreatment of Plant Biomass for Biological and Chemical Conversion to Fuels and Chemicals; Wiley: West Sussex, UK, 2013; pp. 129-143.

14. Fasolini, A.; Cucciniello, R.; Paone, E.; Mauriello, F.; Tabanelli, T. A short overview on the hydrogen production via aqueous phase reforming (APR) of cellulose, C6-C5 sugars and polyols. Catalysts 2019, 9, 917. [CrossRef]

15. Kim, S.M.; Dien, B.S.; Singh, V. Promise of combined hydrothermal/chemical and mechanical refining for pretreatment of woody and herbaceous biomass. Biotechnol. Biofuels 2016, 9, 97. [CrossRef]

16. Wang, Z.; Dien, B.S.; Rausch, K.D.; Tumbleson, M.E.; Singh, V. Fermentation of undetoxified sugarcane bagasse hydrolyzates using a two stage hydrothermal and mechanical refining pretreatment. Bioresour. Technol. 2018, 261, 313-321. [CrossRef] [PubMed]

17. Cheng, M.-H.; Wang, Z.; Dien, B.S.; Slininger, P.J.; Singh, V. Economic analysis of cellulosic ethanol production from sugarcane bagasse using a sequential deacetylation, hot water and disk-refining pretreatment. Processes 2019, 7, 642. [CrossRef]

18. Zhu, W.; Zhu, J.Y.; Gleisner, R.; Pan, X.J. On energy consumption for size-reduction and yields from subsequent enzymatic saccharification of pretreated lodgepole pine. Bioresour. Technol. 2010, 101, 2782-2792. [CrossRef]

19. Overend, R.P.; Chornet, E. Fractionation of lignocellulosics by steam-aqueous pretreatments. Philos. Trans. R. Soc. Lond. Ser. A Math. Phys. Sci. 1987, 321, 523-536.

20. Ertas, M.; Han, Q.; Jameel, H.; Chang, H.M. Enzymatic hydrolysis of autohydrolyzed wheat straw followed by refining to produce fermentable sugars. Bioresour. Technol. 2014, 152, 259-266. [CrossRef]

21. Yang, B.; Tao, L.; Wyman, C.E. Strengths, challenges, and opportunities for hydrothermal pretreatment in lignocellulosic biorefineries. Biofuel Bioprod. Biorefining 2018, 12, 125-138. [CrossRef]

22. Yang, H.; Shi, Z.; Xu, G.; Qin, Y.; Deng, J.; Yang, J. Bioethanol production from bamboo with alkali-catalyzed liquid hot water pretreatment. Bioresour. Technol. 2019, 274, 261-266. [CrossRef] [PubMed]

23. Ko, J.K.; Kim, Y.; Ximenes, E.; Ladisch, M.R. Effect of liquid hot water pretreatment severity on properties of hardwood lignin and enzymatic hydrolysis of cellulose. Biotechnol. Bioeng. 2015, 112, 252-262. [CrossRef]

24. Zakaria, M.R.; Norrrahim, M.N.F.; Hirata, S.; Hassan, M.A. Hydrothermal and wet disk milling pretreatment for high conversion of biosugars from oil palm mesocarp fiber. Bioresour. Technol. 2015, 181, 263-269. [CrossRef]

25. Lynd, L.R.; Elander, R.T.; Wyman, C.E. Likely features and costs of mature biomass ethanol technology. Appl. Biochem. Biotechnol. 1996, 57, 741-761. [CrossRef]

26. Chen, H.; Liu, J.; Chang, X.; Chen, D.; Xue, Y.; Liu, P.; Lin, H.; Han, S. A review on the pretreatment of lignocellulose for high-value chemicals. Fuel Process. Technol. 2017, 160, 196-206. [CrossRef]

27. Leu, S.-Y.; Zhu, J. Substrate-related factors affecting enzymatic saccharification of lignocelluloses: Our recent understanding. Bioenergy Res. 2013, 6, 405-415. [CrossRef]

28. Kumar, D.; Murthy, G.S. Pretreatments and enzymatic hydrolysis of grass straws for ethanol production in the Pacific Northwest US. Biol. Eng. Trans. 2011, 3, 97-110. [CrossRef]

29. de Barros, R.d.R.O.; de Sousa Paredes, R.; Endo, T.; da Silva Bon, E.P.; Lee, S.H. Association of wet disk milling and ozonolysis as pretreatment for enzymatic saccharification of sugarcane bagasse and straw. Bioresour. Technol. 2013, 136, 288-294. [CrossRef] [PubMed]

30. Mosier, N.; Hendrickson, R.; Ho, N.; Sedlak, M.; Ladisch, M.R. Optimization of pH controlled liquid hot water pretreatment of corn stover. Bioresour. Technol. 2005, 96, 1986-1993. [CrossRef] [PubMed]

Publisher's Note: MDPI stays neutral with regard to jurisdictional claims in published maps and institutional affiliations. 